\title{
The Impact of Socio-Pedagogic Equine-Activities intervention on Special Education Pupils with Neurological Disorders.
}

\author{
Ritva Kjäldman, KM, Helsingin yliopisto, Käyttäytymistieteellinen tiedekunta
}

\section{Tutkimuksen tausta}

Tutkimushankkeen nimenä on The Impact of Socio-Pedagogic Equine-Activities intervention on Special Education Pupils with Neurological Disorders. Tutkimus suoritetaan Helsingin yliopiston Käyttäytymistieteellisessä tiedekunnassa soveltavan kasvatustieteen laitoksella.

Tässä tutkimuksessa tutkitaan hevosen ja talliyhteisön avulla tapahtuvaa sosiaalista kuntoutusta ja syrjäytymisen ehkäisyä. Tutkimuksen aihe on poikkitieteellinen (erityispedagogiikka, sosiaalipedagogiikka, psykologia ja antrozoologia). “Talliyhteisö ja hevonen tarjoavat maksimaalisen kokemuksen, joka ei ole verrattavissa muihin, koska se sisältää sekä ainutlaatuisen fyysisen kokemuksen että riemukkaan sosiaalisen ympäristön” (Hart 2000, 94).

Vuonna 2002 Kuopion yliopiston koulutus- ja kehittämiskeskuksessa aloitettiin pilottihankkeena uuden interventiomenetelmän täydennyskoulutus, sosiaalipedagoginen hevostoiminta kasvatus-, sosiaali- ja terveysalan ammattilaisille. Menetelmä on Suomessa uraauurtava yhteisöllisyyden ja eläinavusteisen kuntoutuksen kombinaatio, jonka viitekehys lähtee sosiaalipedagogiikasta. Se voidaan määritellä sosiaalisen kasvun ja hyvinvoinnin tukemiseksi hevosen kanssa tapahtuvassa yhteisöllisessä toiminnassa. Sosiaalipedagogiikan työkäytänteet sisältävät kolme elementtiä: toiminnallisuus, yhteisöllisyys ja elämyksellisyys. Se on luova tieteenala, joka edellyttää rohkeutta kokeilla uusia, erilaisia työskentelytapoja. Pedagogisen suhteen kautta mahdollistetaan perusta yksilön muutokselle ja saadaan aikaan uusi elämänorientaatio, "uinuvan ihmisyyden herättäminen” (Hämäläinen 2002). Tavoitteena on lasten ja nuorten sosiaalisen kasvun ja hyvinvoinnin tukeminen hevosen kanssa tapahtuvassa yhteisöllisessä toiminnassa..

Beck ja Katcher (2001) ovat huomanneet lasten tulevan rauhallisemmiksi eläinten läheisyydessä. Tämä rohkaisee käyttämään eläimiä vaikuttavuuden vahvistajina käyttäytymisen ja sosiaalisten taitojen interventio-ohjelmissa. Eläinavusteiset interventiot jaetaan neljään kategoriaan: lemmikkien vierailuohjelmat, eläinavusteinen terapia, hippoterapia ja terapeuttinen ratsastus (All \& al. 1999, 49-51). Eläimet ja niistä huolehtiminen antaa lapsille mahdollisuuden oppia hoivaamista (Hanselman 2001, 160). Läheinen dialogisuus, tässä ja nyt -oleminen, hoivaaminen, rauhoittuminen ja eläimen menetys ovat aspekteja koskien lasten ja eläinten välisiä siteitä ja bondingia (Melson 2001, 70).

Hevosen käyttäminen kuntoutuksessa on jo useassa maassa pitkään käytetty toimintamalli. Keski-Euroopassa, Yhdysvalloissa sekä Pohjoismaista Ruotsissa ja Tanskassa on talleja, jotka yhteisöllisen ja sosiaalisen kasvun näkökulmasta tekevät työtä lasten ja nuorten syrjäytymiskierteen katkaisemiseksi ja jo syntyneiden vaurioiden korjaamiseksi. Lapset ja nuoret ovat tämän hevostoiminnan piirissä monenlaisten diagnoosien pohjalta Sosiaalipedagogisessa hevostoiminnassa talliyhteisö tiedostaa kokonaisvaltaisen tehtävänsä kasvatuksellisena yhteisönä. Toiminta on turvallisuutta ja vuorovaikutusta herättävä, jonka tavoitteena on vastuullisuuteen ja yhteisöön kasvaminen. Talliyhteisö pyrkii tiedostetusti antamaan vastuuta lapsille ja nuorille, oikeassa suhteessa ikäkauteen ja kehitysedellytyksiin (Koistinen 2005, s. 4-5).

Kaikkein vaikuttavin tapa opettaa ja oppia edellyttää kaikkien aistien käyttämistä. Eläinten kanssa toimiminen antaa lapsille sensorisia kokemuksia (Melson 2001, 79-80.) Taatakseen näiden eläinavusteisten ohjelmien laadun, on merkittävää se, ettei eläimiä käytetä hyväksi vaan niitä kohdellaan tasavertaisina kuntoutuskumppaneina (Fredrickson-MacNamara,and Butler 2006, 140).

Yhdysvalloissa on viimeisen viiden vuoden aikana tutkittu runsaasti hevosen roolia sosiaalistamis-prosesseissa. Psykologian tohtori Kay Sudekum Trotter (2006) tutki riskilasten ohjausta hevosten avulla. Hän löysi tutkimuksessaan tilastollisesti merkitsevää parantumista koeryhmän kokonaiskäytöksessä, positiivisen käytöksen lisääntymisessä ja negatiivisen käytöksen vähenemisessä. Magnell \& al. (2006) tutki hevosavusteisen psykoterapian vaikutusta riskinuoriin. Hänen tutkimuksessaan löydettiin samankaltainen tilastollisesti merkitsevä tulos kokonaiskäytöksen parantumisessa. Lisäksi saatiin tilastollisesti merkitsevä tulos kommunikaatiotaidoissa ja sosiaalisissa taidoissa. 
Heinäkuussa 2008 tutkija matkusti Yhdysvaltoihin, Washburnin yliopistoon Kansasiin, tapaamaan professori Pamelyn MacDonaldia, joka on tutkinut hevosen vaikutusta sosiaalisessa kuntoutuksessa erityisluokkien parissa. Hänen tutkimuksessaan löydettiin tilastollisesti merkitsevät erot tarkasteltaessa hevostoimintaan osallistuneita ryhmiä yksittäisinä tapauksina. Eräässä ryhmässä saatiin tilastollisesti merkitsevä ero itsetunnon kohoamisessa, toisessa hoivaamisen lisääntymisessä ja aggression vähenemisessä.

Ottaessaan vastuuta eläimistä lasten ja nuorten motivaatio ja ymmärrys syvenevät (Melson 2001, 90). Lasten ja nuorten kanssa toimiville aikuisille voidaan antaa kuusi periaatetta, jotka sovellettuina ohjaustyöhön tukevat myönteisen minäkäsityksen muodostumista:

- Anna oppilaan kokea, että opettaja tukee häntä.

- Anna oppilaiden tuntea olevansa vastuullisia ihmisiä.

- Anna oppilaiden tuntea itsensä pystyviksi.

- Opeta oppilaat asettamaan realistiset tavoitteet.

- $\quad$ Auta oppilaita arvioimaan itseään realistisesti.

- Kannusta realistista itsekiitosta (Korpinen 1990).

Omanarvontunnetta ja itsetuntemusta voidaan oppia kokemusten ja elämysten kantta. Hevoskokemusten kautta tämä on mahdollista. Sosiaalipedagogisen hevostoiminnan pilottityössään koulupudokkaiden kanssa tutkija muotoili em. periaatteet talliympäristöön sopiviksi:

- Ohjaaja on mukana auttamassa alkuun. Annetaan yrittää aina itse, mutta ollaan taustalla valmiina.

- Oppilas saa tärkeitä ja merkittäviä tehtäviä (esim. hevosen hyvinvoinnin tai tallin toiminnan kannalta). Hän kokee olevansa tärkeä osa kokonaisuutta.

- Oppilaalle annetaan tallilla kykynsä mukaisia tehtäviä, joiden kautta onnistumisen elämykset ovat mahdollisia.

- Hevostoiminta suunnitellaan yhdessä oppilaan ja ohjaajan kanssa. Toiminnan tulee olla tavoitteellista, mutta se ei saa ylittää eikä alittaa oppilaan suorituskykyä.

- Toiminnan jälkeen käydään se yhdessä läpi. Pohditaan keskustellen asetettujen tavoitteiden kautta miten toiminta sujui. Mietitään mahdollisia muita tapoja toiminnan suorittamiseksi.

- Harjoitellaan olemaan tyytyväisiä omaan suoriutumiseen. Opetellaan löytämään arjesta niitä pieniäkin kiitoksen paikkoja. Opetellaan iloitsemaan pienistäkin onnistumisista ja siirtämään tätä iloa hevostoiminnan ulkopuolelle (Kjäldman 2003, 10).

Opettajan näkökulmasta hevostoiminta oli mielekäs toimintamuoto koulupudokkaiden motivoimiseksi opiskeluun. Talliympäristö poikkesi perinteisestä kouluympäristöstä antaen mahdollisuuden työstää oppiaineita uudella tavalla. Hevostoiminta avasi uudenlaisen pedagogisen suhteen opettajan ja oppilaan välille. Oppitunnit olivat aidommin vastavuoroisia kuin perinteisessä kouluopetuksessa. Parhainta antia olivat tunne kasvamisesta kunnioitukseen toista kohtaan, luottamuksen lisääntymiseen, vastuullisuuteen, ymmärtämiseen ja kokemusten kohtaamisiin ainutkertaisina (Kjäldman 2003, 20).

\section{Tutkimuksen tavoitteet}

Tutkimuksen tavoitteena on saada vastaus seuraaviin tutkimusongelmiin:

1. Onko sosiaalipedagogisella hevostoiminnalla vaikuttavuutta erityisluokkien oppilaiden sosiaalisten taitojen ja psykodynaamisen kasvun vahvistumisessa?

2. Voidaanko sosiaalipedagogisella hevostoiminnalla vahvistaa pedagogisen suhteen syventymistä ohjaajan (opettajan) ja oppilaan välillä?

3. Onko hevosen läsnäololla toiminnassa merkitystä sosiaalipedagogisen hevostoiminnan prosessissa psykodynaamisen kasvun tukijana?

\section{Hypoteesit}

1. Sosiaalipedagogisella hevostoiminnalla on positiivista vaikuttavuutta erityisoppilaiden itsetuntoon ja aggression vähentymiseen (Bizub et al. 2003; Glazer 2004; Bradberry 2006; Frame 2006;

Hemenway 2007; Klontz 2007; MacDonald 2007)

2. Sosiaalipedagoginen hevostoiminta lisää erityisoppilaiden verbaalista kommunikointia, tarkkaavaisuutta ja itsesäätelyä (MacKinnon 1995; Lehrman 2001; MacDonald 2007)

3. Sosiaalipedagogisella hevostoiminnalla on vaikuttavuutta ja pysyvyyttä erityisoppilaan arjen hallintaan (aggression hallinta, empatiakyky, itsesäätely ja kaverisuhteet). 


\section{Tutkimuksen toteuttaminen ja aikataulu}

Tutkimukseeni koostuu sekä kvalitatiivisesta että kvantitatiivisesta osasta. Kvalitatiivisella (haastattelut, $\mathrm{N}=7-8$ ) osuudella pyritään selvittämään, miten aiemmin sosiaalipedagogiseen hevostoimintaan osallistuneet erityistä tukea tarvinneet nuoret (vuosina 2002 - 2005) kokivat toiminnan: oliko toiminnalla merkitystä heidän senhetkisen tilanteensa ratkaisuun, auttoiko toiminta arkielämässä selviytymiseen sekä miten he kokivat hevosen roolin sosiaalisten taitojen vahvistamisessa ja psykodynaamisessa kasvussa. Kvalitatiivisen tutkimuksen koehenkilöt ovat aiemmin sosiaalipedagogiseen hevostoimintaan ohjattua oppilaita koulujensa kautta. Heille suoritetaan haastattelututkimus. Haastattelun tuottamaa aineistoa tarkasteltaessa pyritään löytämään yhteneviä muistoja siitä, mikä hevostoiminnassa oli merkittävää.

Kvantitatiivisessa osuudessa mitataan sosiaalipedagogisen hevostoiminnan vaikuttavuutta erityisluokan oppilaiden sosiaalisten taitojen kehittymisessä. Kvantitatiivisen tutkimuksen koe- ja kontrolliryhmien henkilöt ovat espoolaisia erityisluokkien oppilaita. Heille suoritetaan mittaukset kyselylomakkein ennen interventiota, intervention päätyttyä sekä puoli vuotta intervention päättymisen jälkeen. Lisäksi tietoa kerätään kyselylomakkein heidän opettajiltaan, koulunkäyntiavustajiltaan että huoltajiltaan (samoina ajankohtina kuin oppilailta). Kyselylomakkeiden tuottamaa aineistoa tarkastellaan SPSS-ohjelmalla. Koeryhmän hevostoiminta pohjautuu K.S. Trotterin kehittämään interventiomanuaaliin EPIC-Training: treating at-risk youth and adolescents with equine assisted counseling (Trotter 2006, s. 153-197).

Koeryhmän lisäksi tutkimukseen osallistuu kolme kontrolliryhmää, joista ensimmäiselle järjestetään luokkahuoneessa tapahtuvaa standardoitua sosiaalisten taitojen harjoittelua (ARTinterventio) ja toiselle kontrolliryhmälle pidetään matematiikan tunteja. Kolmas kontrolliryhmä ei saa mitään interventiota tai tavallisuudesta poikkeavaa toimintaa. Tutkija suorittaa mittaukset ennen interventiota, interventioiden päättyessä sekä puoli vuotta päättymisen jälkeen. Mittaukset suoritetaan oppilaille, huoltajille, opettajille ja koulunkäyntiavustajille suunnatuilla kyselylomakkeilla.

Tutkimus on saanut tutkimusluvan Espoon suomenkieliseltä koulutuskeskukselta. Lisäksi pyydetään kirjallinen lupa kunkin oppilaan huoltajilta tutkimukseen osallistumista varten. Oppilas saa olla mukana sosiaalipedagogisessa hevostoiminnassa luokkansa kanssa, vaikka huoltajat eivät antaisi hänelle lupaa osallistua tutkimukseen.

Tutkimuksessa käytettävää sosiaalipedagogista hevostoimintaa suoritettaessa otetaan huomioon eläinsuojelulliset näkökohdat, hevosten olosuhteisiin ja hyvinvointiin kiinnitetään erityistä huomiota (Saastamoinen 2008, 39).

Tutkimushankkeen kannalta keskeinen kansallinen ja kansainvälinen yhteistyö ja työnjako Tutkijalla on kontakti Yhdysvaltoihin (MacDonald, Emporia State University, Kansas) sekä hevostoiminta-intervention kehittäneeseen ja sitä testanneeseen K.S. Trotteriin. Molemmat ovat väitelleet hevosten kuntouttavasta vaikutuksesta erityistä tukea tarvitsevien lasten ja nuorten sosiaalistamisprosessissa. He ovat molemmat luvanneet tarkastaa sekä tutkimukseni kieliasua että sisältöä. Tutkija on mukana työryhmässä ”Botnia-Atlantica”, jossa tutkimaan eläinten kuntouttavaa vaikutusta. Pro-jektin vetäjä on Carina Nilsson Ruotsista. Projekti käynnistyy helmikuun lopulla 2009. Osallistuminen pro-jektiin tuottaa yleistä tietoa eläinten kuntouttavasta vaikutuksesta, mutta myös tietoa siitä, miten Ruotsissa hevosia käytetään ratsastusterapian ja vammaisratsastuksen lisäksi erityistä tukea tarvitsevien lasten ja nuorten syrjäytymisen ehkäisemiseksi. Elokuussa 2009 tutkija esittelee tutkimuksensa yhteiseurooppalaisessa ESRS tutkijakongressissa Vaasassa. Kongressin vastuullisena järjestäjänä on Åbo Akademin.

Tutkimuksen odotettu tieteellinen ja yhteiskunnallinen vaikuttavuus

Mikäli tutkimustulokset osoittavat tilastollisesti merkitseviä tuloksia erityisoppilaiden sosiaalisessa kasvussa, voidaan todeta tämän interventiomenetelmän olevan yhteiskunnalle suhteellisesti halvempi ennaltaehkäisevä tai korjaava menetelmä kuin lasten yksilöterapiat. Talliympäristö kasvuympäristönä tarjoaa lapsille ja nuorille virikkeitä, liikuntaa ja raitista ilmaa tukien heidän hyvinvointiaan ja jaksamistaan.

Syrjäytyminen ja toimet sen ehkäisemiseksi ovat ajankohtaisia asioita. Yhteiskunnan tasolla on kiinnitetty viime aikoina paljon huomiota lasten ja nuorten syrjäytymiseen. Mm. hallitusohjelmissa on 2000-luvulla kiinnitetty huomiota tähän: "Jokaisella on tasavertainen oikeus saada edellytystensä mukaista koulutusta elinikäisen oppimisen periaatteen mukaan. Syrjäytymisen ehkäisemiseksi 
painotetaan lasten ja nuorten oikeutta henkisesti ja fyysisesti turvalliseen kasvuympäristöön.” Tärkeää on jokaisen lapsen ja nuoren hyvinvoinnin lisääminen yksilönä syrjäytymiskehitystä ehkäisemällä (Jäppinen 2003).

Mahdollisuus tieteellisiin läpimurtoihin ja tutkimuksen ja tieteen uusiutumiskyvyn lisäämiseen

Interventiotutkimukset ovat merkittäviä, koska niissä testataan uusien menetelmien vaikuttavuutta ja sopivuutta. Tutkimuksella saattaa olla merkittävä vaikutus uusien varhaisen ja tehostetun tuen menetelmien käyttöönottamisella. Mikäli tutkimuksen tuottama tulos on samansuuntainen viimeaikaisten yhdysvaltalaisten tutkimusten kanssa, on tällä vain 12 kerran interventio-menetelmällä mahdollista saada tilastollisesti merkitsevä kohoaminen erityistä tukea tarvitsevien lasten ja nuorten positiivisessa käyttäytymisessä sekä negatiivisen käyttäytymisen vähenemisessä. Hevosavusteinen menetelmä sai Trotterin tutkimuksessa aikaan enemmän positiivisia muutoksia kuin kontrolliryhmän saama luokkahuoneessa tapahtuva opintojen ja oppimisen ohjaus.

Tutkimus on vaikuttavuustutkimus, jossa testataan uuden sosiaalisen kuntoutuksen interventiomenetelmän vaikuttavuutta erityisoppilailla. Tarkoituksena on lisäksi kansainvälisten olemassa olevien vaikuttavuustutkimusten normien ja tilastollisesti merkitsevien tulosten vertaaminen ja soveltaminen suomalaisessa kuntoutus- ja tukijärjestelmässä. Näitä suomalaisia vaikuttavuuden ja tuloksellisuuden normeja/raja-arvoja voitaisiin hyödyntää korvauskäytännön perusteina (vaikuttavuus).

Valtaosa suomalaisista lapsista ja nuorista voi hyvin, mutta tietyt erityistä tukea tarvitsevat lapset ja nuoret tarvitsevat riittävän tehokkaita interventioita sosiaalisen kasvunsa ja elämänhallintansa tueksi. Sosiaalipedagoginen hevostoiminta voi olla sellainen uusi menetelmä, jolla turvata näiden lasten ja nuorten koulutus sekä psyykkinen ja fyysinen hyvinvointi.

Sosiaalipedagogisen hevostoiminnan täydennyskoulutusta järjestävät tahot hyödyntänevät tutkimustuloksia sekä koulutusohjelmissaan että tiedottaessaan toiminnasta julkiselle sektorille (mm. kuntien sosiaaliviranomaiset). Tutkijan tavoitteena on tutkimuksen valmistuttua kirjoittaa keskeisimmistä tutkimustuloksista artikkelit kansainvälisiin tiedejulkaisuihin. Suomen Ratsastajainliitto vastaa tutkimustulosten julkaisemisesta alansa lehdessä.

Tutkimuksen viitekehys on sekä erityis- että sosiaalipedagoginen. Kohderyhmänä ovat erityistä tukea tarvitsevat lapset ja nuoret, jotka ovat valikoituneet erityisluokille oppimisen erityis-vaikeuksien vuoksi. Interventiomenetelmänä käytetään sosiaalipedagogiseen viitekehykseen pohjaavaa menetelmää, sosiaalipedagogista hevostoimintaa. Sosiaalipedagogisessa hevostoiminnassa on keskeistä ihmisen ja hevosen vuorovaikutus sekä yhteisö, jossa toiminta tapahtuu.

Tutkimuksen aikataulu

Teoreettinen viitekehys

2006-2008

Tutkimusmenetelmät

2007-2009

Jatko-opinnot (metodi- ja aineopinnot)

2006-2008

Haastattelut ja interventiot

$2009-2010$

Raportointi

2010-2012

\section{Lähteet:}

All, A.C., Loving, G.L. and Crane, L.L. (1999). Animals, Horseback Riding and Implications for Rehabilitation Therapy. Journal of Rehabilitation, Vol. 65(3, Jul/Aug), 49-57.

Beck, A.M. and Katcher, A.H. (2003). Future Directions in Human-Animal Bond Research. The American Behavioral Scientist 47 (1), 79-93.

Beck, A. and Katcher, A.H. (2001). Between Pets and People: The Importance of Animal Companionship. In Hanselman, J.L. Coping Skills Interventions with Adolescents in Anger Management Using Animals in Therapy. Journal of Child and Adolescent Group Therapy Vol. 11( 4), 159-195.

Bizub,A.L., Joy, A. and Davidson, L. (2003). It's like being in another world: Demonstrating the benefits of therapeutic horseback riding for individuals with psychiatric disability. Psyciatric Rehabilitation Journal 26(4), 377-384.

Bradberry, J.M. (2006). Lived Experienceof Equine Facilitated Psychotherapy in Adult Female Survivors of Abuse. Adult Mental Health Issues and Innovations Presentation July 20.

Hanselman, J.L. (2001). Coping Skills Interventions with Adolescents in Anger Management Using Animals in Therapy. Journal of Child and Adolescent Group Therapy Vol. 11( 4), 159195. 
Hart, A.M. (2000). Methods standards, guidelines, and considerations in selecting animals for animal assisted therapy. In A.Fine (Eds.) Animal assisted therapy (pp. 81-114). San Diego: Academic Press.

Hemenway, R. (2007). Effects of Horseback riding on Depression and Self-Esteem in adolescent girls. Dissertation Abstracts International: Section B: the Sciences and Engineering 67 (7B), 4133-4304.

Hämäläinen, J. (2002). Julkaisemattomat luentomuistiinpanot. Kuopion yliopiston kehittämis- ja koulutuskeskus 25.10.2002

Frame, D.L. (2006). Practices of Therapists using Equine Facilitated/Assisted Psychotherapy in the Treatment of Adolescents diagnosed with Depression: A Qualitative study: Dissertation Abstracts International Section A: Humanities and Social Sciences 67 (2-A), 718.

Fredrickson-MacNamara, M. and Butler, K. (2006). The Art of Animal Selection for Animal-Assisted Activity and Therapy Programs. In A. Fine (Ed.), Animal-Assisted Therapy. (pp. 121147). San Diego: Academic Press.

Friedmann, E., Katcher, A.H., Lynch, J.J. and Thomas, S.A. (1999). Animal Companions and OneYear Survival of Patients after Discharge from a Coronary Care Unit. In All, A.C., Loving, G.L. and Crane, L.L. (1999). Animals, Horseback Riding and Implications for Rehabilitation Therapy. Journal of Rehabilitation, Vol. 65(3, Jul/Aug), 49-57

Glazer. H.D., Clarck, M.D. and Stein, D.S. (2004). The impact of hippotherapy on grieving children. Journal of Hospice and Palliative Nursing 6, 171-175

Jäppinen, A. (2003). Lasten ja nuorten syrjäytymisen ennaltaehkäisy. Seminaaripuhe 26.5.2003

Katcher, A. and Teumer, S. (2006). A 4-Year Trial of Animal-Assisted Therapy with Public School Special Education Students. In A. Fine (Ed.), Animal-Assisted Therapy. (pp. 227-242). San Diego: Academic Press.

Kjäldman, R. (2003). Putosin koulusta, nousin ratsaille. Projektityö. Kuopion yliopiston täydennyskoulutuskeskus.

Kjäldman, R. (2005). Putosin koulusta, nousin ratsaille. Ratsastuspedagoginen lähestymistapa koulupudokkaiden yksityisopetuksessa. Teoksessa Okulov, S. (toim.).

Ratsastuspedagogiikasta sosiaalipedagogiseksi hevostoiminnaksi: sosiaalipedagogisen hevostoiminnan perusteet ja sovellukset täydennyskoulutuksen kokemina Kuopion yliopiston Koulutus- ja kehittämiskeskus.Tutkimuksia ja selvityksiä 7/2005 (s. 35-43).

Klontz, B.T, Bivens, A, Leinart, D. and Klontz, T. (2007). The Effectiveness of Equine-Assisted Experimental Therapy: Results of an Open Clinical Trial. Society and Animals 15 (3), 257-267.

Koistinen, K. (2005). Hevostoiminta ehkäisemään lasten ja nuorten syrjäytymistä. Teoksessa Okulov, S. (toim.). Ratsastuspedagogiikasta sosiaalipedagogiseksi hevostoiminnaksi: sosiaalipedagogisen hevostoiminnan perusteet ja sovellukset täydennyskoulutuksen kokemina (s. 1-10). Kuopion yliopiston Koulutus- ja kehittämiskeskus. Tutkimuksia ja selvityksiä 7/2005.

Korpinen, E. (1990). Peruskoululaisen minäkäsitys. Jyväskylä: Kasvatustieteiden tutkimuslaitoksen julkaisusarja A. Tutkimuksia 34.

Lehrman, J. and Ross, D.B. (2001). Therapeutic Riding for a Student with Multiple Disabilities and Visual Impairment: A Case Study. Journal of Visual Impairment Therapy and Blindness 95, 108-109.

MacDonald, P. (2004). The effects of equine-facilitated therapy with at-risk adolescents: A summary of empirical research across multiple centers and programs. The Center for the Interaction of Animals and Society (CIAS). Philadelphia: University of Pennsylvania School of Veterinary Medicine

Melson, G.F. (2001). Why the Wild Things are: Animals in the Lives of Children. Cambridge: Harvard University Press.

Saastamoinen, M. (2008). Terapiatyöskentely hevoselle raskasta. ProHevonen 4/2008 (s. 39).

Trotter, K.S. (2006). The Efficacy of Equine Assisted Group Counseling with at-risk Children and Adolescents. University of North Texas. Doctoral Dissertation. 